\title{
Locke, expressivism, conditionals
}

\author{
Frank Jackson \& Philip Pettit
}

\section{Introduction}

The sentence ' $x$ is square' might have had different truth conditions from those it in fact has. It might have had no truth conditions at all. Its having truth conditions and its having the ones it has rest on empirical facts about our use of ' $x$ is square'. What empirical facts? Any answer that goes into detail is inevitably highly controversial, but we think that there is a rough answer that is, by philosophers' standards, relatively uncontroversial. It goes back to Locke 1689 and beyond, and is best known to contemporary philosophers through the work of Grice 1957 and Lewis 1969. It is that we (usually implicitly) agreed, as a matter of contingent fact, to use ' $x$ is square' as a way of conveying our taking it to be the case that $x$ is square.

In Jackson and Pettit 1998 we argue that this Lockean picture makes trouble for expressivism in ethics. Expressivists hold that ' $x$ is good', for example, expresses a certain pro-attitude towards $x$. But it does not report the attitude; indeed, it does not report anything, which is how expressivists reach their distinctive position that ' $x$ is good' lacks truth conditions. But we acquire ethical language through a process of entering agreements to use ethical language in certain circumstances, and we argued that expressivists have to hold that we learn to use ' $x$ is good' when we believe that we have the relevant pro-attitude - they can hardly hold that we learn to use it when we have no idea what our attitudes are or believe them to be negative towards $x$ - and want to convey this fact. However, on the Lockean picture, entering this kind of agreement is what it is for ' $x$ is good' to be true if and only if the speaker has the relevant pro-attitude towards $x$. If the Lockean picture is correct, there is, as a thesis in the philosophy of language, no room for expressivism in the constellation of ethical theories. 
Of course expressivists were right to point out that 'hooray' expresses approval without reporting it and without having truth conditions. But 'hooray' is not part of a set of fine-grained, detailed agreements in the way ethical terms must be if we are to make sense of their role in ethical debate. It could have been, in which case it would have had truth conditions but, as a matter of fact, it isn't.

That, in a nutshell, was our argument from Locke against expressivism. Smith and Stoljar 2003 argue that, without calling into question the Lockean picture, you can see that our argument fails. It overlooks the key distinction between agreements for and agreements when and, they go on to argue, this distinction is crucial to understanding how indicative conditionals might lack truth conditions despite the fact we acquire the indicative conditional construction through a process of entering agreements to use it in certain circumstances. So, on their view, the example of indicative conditionals nicely bolsters their case for the importance of this distinction.

\section{Agreements when and for}

Smith and Stoljar encapsulate the Lockean picture for 'square' in two claims (we quote)

'Agreement Claim (square):

We agreed to (sincerely) use “ $x$ is square” for $x$ 's being square.'

'Belief Claim (square):

Acting on this agreement means using " $x$ is square" when we believe that $x$ is square.'

They suggest that our argument is that, analogously, expressivists must allow that we have in the case of 'good' (again we quote)

'Agreement Claim (good):

We agreed to (sincerely) use " $x$ is good" when we approve of $x$.'

\section{'Belief Claim (good):}

Acting on this agreement means using " $x$ is good" when we believe that we approve of $x$.'

They then represent us as concluding from the analogy between the two cases that expressivists must allow that 'square' and 'good' are alike in standing for something and as forming truth-evaluable sentences: ' $x$ is square (good)' being true iff $x$ has that which 'square (good)' stands for.

They are right that there is a problem for the argument as they represent it. The cases are not sufficiently analogous. The Agreement Claim in the case of 'square' is expressed in terms of an agreement for, the Agreement Claim in the case of 'good' is expressed in terms of an agreement when, and 
it might well be argued by expressivists that this difference matters. They might grant that we agreed to use 'good' when we have certain proattitudes while denying that we use 'good' for those attitudes, or indeed anything else in the sense of 'for' that delivers truth-evaluability.

However, this was not our argument. Our argument derives from the Lockean picture and that picture is not captured by the two clauses they give for the word 'square'. The right way to encapsulate the Lockean picture for 'square' is with three theses. We say 'encapsulate', as the full Lockean story is complex. We follow Smith and Stoljar in leaving out the bells and whistles in the interests of focusing on the key issues.

\section{$\left(\mathrm{A}_{1}\right)$ Locke's Claim (square):}

What it would be to use ' $x$ is square' to stand for $x$ 's being such and such is to agree to use ' $x$ is square' when we believe that $x$ is such and such and that conditions are right for communicating this fact. ${ }^{1}$

\section{$\left(\mathrm{B}_{1}\right)$ Belief Claim (square):}

We agreed to use ' $x$ is square' when we believe that $x$ is square and that conditions are right for communicating this fact.

\section{$\left(\mathrm{C}_{1}\right)$ Agreement Claim (square):}

We agreed to use ' $x$ is square' for $x$ 's being square.

$\left(A_{1}\right)$ is Locke's general position stated for the case of 'square'. In terms of the distinction between agreements for and agreements when, it is the view that certain kinds of agreements when are agreements for. To agree at a police line-up to nod when you are in front of the person you believe attacked you is to agree to use a nod for the guilty party. In entering the agreement when, you settle what the nod is for. After entering the agreement, would you say 'Hold on, I don't know what the nod is for'? What the nod is for supervenes on your agreement about when to use it. Or take the international conventions governing the flying of various flags on buoys to indicate diver below or dangerous reef, for example. It would be bizarre for someone who understood when it had been agreed to fly the various flags to complain that they did not know what the flags signified or were for. Smith and Stoljar conclude their paper with 'The crucial thing is what, if anything, you agreed to use your words for, not what you believe when you use your words.' But that's not the issue. The issue is whether agreeing to use words when you believe such and such and that conditions are right for communicating this fact is to agree to use your words for such and such. We follow Locke in saying that it is.

${ }^{1}$ Although we are sliding over the complexities, we should footnote that 'conditions are right for communicating this fact' must of course be understood in terms of communicative intentions, knowledge of one's audience and of likely consequences of utterance, and all that. The 'right' is not a moral one. 
$\left(B_{1}\right)$ is the matter of empirical fact that settles the truth conditions of ' $x$ is square'. Had we instead agreed to use ' $x$ is square' when we believe that $x$ is round and that conditions are right for communicating this fact, ' $x$ is square' would have been true iff $x$ is round.

$\left(\mathrm{C}_{1}\right)$ follows from $\left(\mathrm{A}_{1}\right)$ and $\left(\mathrm{B}_{1}\right)$.

In similar fashion, our argument in the case of 'good' can be given in three claims.

$\left(\mathrm{A}_{2}\right)$ Locke's Claim (good):

What it would be to use ' $x$ is good' to stand for $x$ 's being such and such is to agree to use ' $x$ is good' when we believe that $x$ is such and such, and that conditions are right for communicating this fact.

$\left(\mathrm{B}_{2}\right)$ Belief Claim (good):

We agreed to use ' $x$ is good' when we believe that we approve of $x$ and that conditions are right for communicating this fact.

$\left(\mathrm{C}_{2}\right)$ Agreement Claim (good):

We agreed to use ' $x$ is good' for $x$ 's being approved of by us.

$\left(A_{2}\right)$ is Locke's general position stated for 'good'.

$\left(B_{2}\right)$ is, we argue in Jackson and Pettit 1998, something expressivists are committed to from what they have to hold about how we came to acquire the word 'good' and like ethical terms. For example, expressivists can hardly hold that we agreed to use ' $x$ is good' when we have no idea whether or not we approve of $x$. In this context, it is worth noting a passage from Blackburn:

what is done when we say such things [e.g. ' $x$ is good']. We avow a practical state. 'Avowal' here means that we express this state, make it public, or communicate it. We intend coordination with similar avowals or potential avowals from others, and this is the point of communication. (1999: 68, our emphases)

Presumably we are in a position to avow a state when we believe that we are in the state. If so, the passage is very much in line with $\left(\mathrm{B}_{2}\right)$ and in the tradition of Lockean views about language.

$\left(\mathrm{C}_{2}\right)$ follows from $\left(\mathrm{A}_{2}\right)$ and $\left(\mathrm{B}_{2}\right)$, and amounts to our conclusion that the Lockean picture means that expressivism collapses into a kind of subjectivism.

\section{Indicative conditionals}

Smith and Stoljar rightly see indicative conditionals as a test case. Whether or not indicative conditionals have truth conditions is an open question in the sense that it calls for detailed consideration. For example, we agree with those who hold that it would be too quick to say that because indicative 
conditionals are meaningful and allow the appending of the truth predicate, they must have truth conditions, and we see this as a problem for some versions of minimalism about truth aptness. Smith and Stoljar think we are committed by our Lockean argument against expressivism to a similarly 'too quick' answer. They consider the appealing idea from Adams 1975 that to master the indicative conditional construction is to learn that the right occasion for using 'If it rains, the match will be cancelled' 2 is when the probability of the match being cancelled given rain is high, and rightly point out that it would be wrong to infer from this and Lockean views of language without further ado that the sentence has truth conditions. However, the Lockean view, far from being so committed, explains why it is an open issue whether or not indicative conditionals have truth conditions in terms of Adams's appealing idea.

As we saw above, the Lockean approach is encapsulated in three claims. As applied to indicative conditionals, the claims are

$\left(\mathrm{A}_{3}\right)$ Locke's Claim ('If it rains, the match will be cancelled'):

What it would be to use 'If it rains, the match will be cancelled' to stand for such and such is to agree to use 'If it rains, the match will be cancelled' when we believe that such and such, and that conditions are right for communicating this fact.

( $\left.\mathrm{B}_{3}\right)$ Belief Claim ('If it rains, the match will be cancelled'):

We agreed to use 'If it rains, the match will be cancelled' when we believe that $Z$, and that conditions are right for communicating this fact.

$\left(\mathrm{C}_{3}\right)$ Agreement Claim ('If it rains, the match will be cancelled'): We agreed to use 'If it rains, the match will be cancelled' for $Z$.

$\left(A_{3}\right)$ is Locke's generic claim stated for 'If it rains, the match will be cancelled'. $\left(C_{3}\right)$ follows from $\left(A_{3}\right)$ and $\left(B_{3}\right)$. The key issue is whether or not $\left(B_{3}\right)$ is true for any $Z$. As we said above, Smith and Stoljar point out that many have found something like $\left(\mathrm{B}_{3}{ }^{*}\right)$ appealing.

$\left(\mathrm{B}_{3}{ }^{*}\right)$ Conditional Probability Claim ('If it rains, the match will be cancelled'):

We agreed to use 'If it rains, the match will be cancelled' when our conditional probability for the match being cancelled given rain is high, and we believe that conditions are right for communicating this fact.

But although $\left(\mathrm{B}_{3}{ }^{*}\right)$ gives conditions under which we agreed to use 'If it rains, the match will be cancelled', these conditions are not of the right

2 They use 'If it rains, the match is cancelled', but this is naturally read as 'Whenever it rains the match is cancelled', so it seems safer to use the more familiar example. 
form to apply Locke's approach to deliver truth conditions without further ado. ${ }^{3}$ This is because a conditional probability is not the probability of a proposition. ${ }^{4}$ Smith and Stoljar are, therefore, mistaken in thinking that we are committed to the issue for ethical sentences and the issue for indicative conditionals being essentially the same. There is a major problem about finding a true (B)-type claim of the right kind to deliver truth conditions in the case of indicative conditionals that does not apply in the case of ethical sentences given expressivist views.

Although $\left(\mathrm{B}_{3}{ }^{*}\right)$ does not deliver truth conditions (or not without further ado) for indicative conditionals, it is Lockean in the following sense. The clause that follows 'when' concerns speakers' epistemic states because the relevant notion of probability is the degree of belief notion. The trouble for expressivists that we pressed is that the only epistemic states available for them to appeal to in accounting for our voluntary agreements to use ethical terms in the way we do are subjects' beliefs about their attitudes, and doing that delivers truth conditions for ethical sentences. By contrast, theorists of indicative conditionals can appeal to conditional degrees of belief in consequents given antecedents. ${ }^{5}$

Research School of Social Sciences The Australian National University Canberra, ACT 0200, Australia frank.jackson@anu.edu.au

\section{Department of Politics and Philosophy Princeton University Princeton, NJ 08544-1012, USA ppettit@princeton.edu}

${ }^{3}$ One of us, see Jackson 1979, thinks, controversially, that with 'further ado' it is possible on the ground that:

We agreed to use 'If it rains, the match will be cancelled' when a) we believe that either it will not rain, or it will and the match will be cancelled, and b) that belief is resilient with respect to its raining, and c) we believe that conditions are right for communicating this fact

is true and near enough to the required form to give 'If it rains, the match will be cancelled' the truth conditions of 'Either it will not rain, or it will and the match will be cancelled'.

4 The issues here have been widely discussed, especially post the proof in Lewis 1976 that the probability of a conditional cannot in general be identical with the conditional probability of its consequent given its antecedent.

5 Thanks to Michael Smith and Daniel Stoljar for many discussions that, despite not leading to consensus, greatly clarified the disagreements. 


\section{FRANK JACKSON \& PHILIP PETTIT}

\section{References}

Adams, E. 1975. The Logic of Conditionals. Dordrecht: Reidel. Blackburn, S. 1999. Ruling Passions. Oxford: Clarendon Press.

Grice, H. P. 1957. Meaning. Philosophical Review 66: 377-88.

Jackson, F. 1979. On assertion and indicative conditionals. Philosophical Review 88: 565-89.

Jackson, F. and P. Pettit. 1998. A problem for expressivism. Analysis 58: 239-51.

Lewis, D. 1969. Convention. Cambridge, Mass.: Harvard University Press.

Lewis, D. 1976. Probabilities of conditionals and conditional probabilities. Philosophical Review 75: 297-315.

Smith, M. and D. Stoljar. 2003. Is there a Lockean argument against expressivism? Analysis, this issue. 